\title{
Fabricating plasmonic components for nanophotonics [invited]
}

Boltasseva, Alexandra; Nielsen, Rasmus Bundgaard; Jeppesen, Claus; Kristensen, Anders; Bakker, R.; Liu, Z.; Yuan, H.K.; Kildishev, A.V.; Shalaev, V.M.

\section{Published in:}

IEEE/LEOS Winter Topical Meetings

Link to article, DOI:

10.1109/LEOSWT.2009.4771647

Publication date:

2009

Document Version

Publisher's PDF, also known as Version of record

Link back to DTU Orbit

Citation (APA):

Boltasseva, A., Nielsen, R. B., Jeppesen, C., Kristensen, A., Bakker, R., Liu, Z., Yuan, H. K., Kildishev, A. V., \& Shalaev, V. M. (2009). Fabricating plasmonic components for nanophotonics: [invited]. In IEEE/LEOS Winter Topical Meetings IEEE. https://doi.org/10.1109/LEOSWT.2009.4771647

\section{General rights}

Copyright and moral rights for the publications made accessible in the public portal are retained by the authors and/or other copyright owners and it is a condition of accessing publications that users recognise and abide by the legal requirements associated with these rights.

- Users may download and print one copy of any publication from the public portal for the purpose of private study or research.

- You may not further distribute the material or use it for any profit-making activity or commercial gain

- You may freely distribute the URL identifying the publication in the public portal 


\title{
Fabricating plasmonic components for nanophotonics
}

\author{
A. Boltasseva, R. Bakker, Z. Liu, H.-K. Yuan, A. V. Kildishev, V. M. Shalaev \\ Birck Nanotechnology Center, Purdue University \\ West Lafayette, IN 47907, USA \\ Tel: + 1 (765) 494 0301; email: aeb@ purdue.edu
}

\section{R. B. Nielsen, C. Jeppesen, A. Kristensen}

Technical University of Denmark

DTU Building 343, DK-2800 Kongens Lyngby, Denmark

\begin{abstract}
We report on experimental realization of different metal-dielectric structures that are used as surface plasmon polariton waveguides and as plasmonic metamaterials. Fabrication approaches based on different lithographic and deposition techniques are discussed.
\end{abstract}

Modern nanofabrication techniques opened new possibilities for controlling and preparing profiled and patterned metal surfaces in order to tailor the properties of surface plasmon polaritons (SPPs) excited on the metal-dielectric interfaces and nanoparticles. Properties of SPPs (strong localization, sensitivity to surface topology) make plasmonic structures based on different metal-dielectric geometries very attractive candidates for developing new devices for integrated optics and sensors. A variety of promising configurations for SPP directional propagation, bending, focusing and localization have been reported [1]. Metal-dielectric geometries for guiding and manipulation of SPPs range from special configurations of nanoscatterers on metal surfaces [2] and metal strips [3] or wires [4] to profiled metal surfaces [5]. Plasmonic resonance of paired gold nanoparticles (optical nanoantennae) gives rise to high field confinement that is important for sensing and tagging applications, nanoscale lithography, and as the basis for nanolasers [6, 7]. Here, we consider fabrication of metal-dielectric configurations and thin metal layers that require development of nanoscale patterning tools and productioncompatible techniques for structures with real-device applications potential.

Profiled metal surfaces as plasmonic waveguides. Coupling of SPPs on opposite sidewalls of either a channel or wedge made in metal leads to formation of highly localized plasmonic modes that can be used for making compact optical components [5]. Since profiling of the metal surfaces requires complex and expensive techniques as focused ion beam milling and can not be done via standard etching techniques, we developed a wafer-scale fabrication method that is based on standard planar cleanroom processes and allows integration of plasmonic structures with lab-on-chip devices. The main idea of the method is to make a metal replica of a profiled silicon structure where any desired geometry can be obtained via standard patterning and etching techniques. The approach is based on nanoimprint lithography (NIL) that is used to transfer structures from a silicon stamp to a NIL polymer and then create a gold-on-polymer replica of the initial silicon stamp (Fig. 1). In addition to large-scale fabrication using standard processes offered by the method, using the backside of the metal film deposited on a polymer layer reduces the surface roughness, similar to the process of template-stripping [8], though the PMMA film used is not ideally flat.

Nanoantennae / Plasmonic metamaterials. A dipole antenna consisting of paired metal nanoparticles, like the bow-tie antenna or adjacent metal rods [6] is of particular interest for potential applications in sensing and imaging. Fabrication of nanoantenna arrays made of paired elliptical gold particles is reported here for particle sizes down to several tens of $\mathrm{nm}$ and gaps between particles down to $15 \mathrm{~nm}$, and the structural dimensions (size, gap) influence on the resonance is discussed. Antenna arrays were 
fabricated for two different configurations: with particles placed on a transparent (quartz) substrate and embedded in the substrate for future applications where plasmonic resonators are to be combined with a flat superlens [9]. Fabrication challenges (surface roughness, sub-15nm gaps) are also discussed.

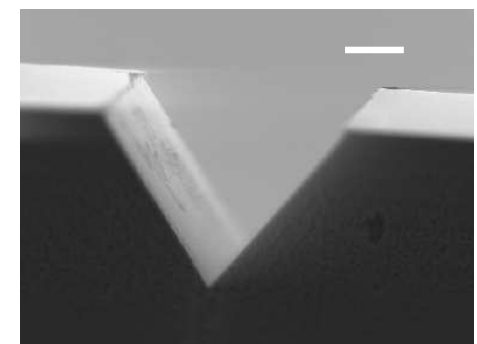

(a)

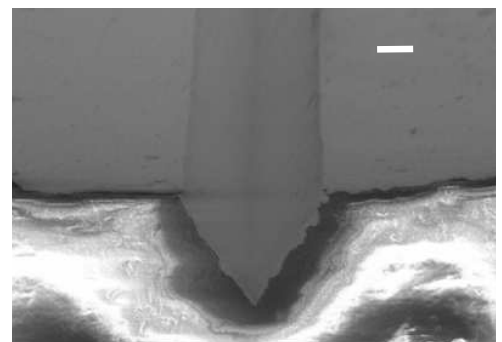

(b)

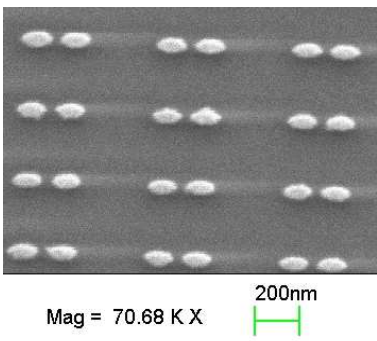

(c) on top of a transparent polymer, white bars are $2 \mu \mathrm{m}$, (c) antenna array on top of a quartz substrate.

The performance of plasmonic structures as well as possible applications depends greatly on the fabrication methods used. Thus, it is important to investigate different fabrication possibilities and find the robust, low cost and mass-production compatible method of manufacturing plasmonic components. The manufacturing procedure suitable for real device applications should offer simplicity of using only standard cleanroom processes, high reproducibility, and low cost, combined with the possibility of adapting the process for various designs. Moreover, improving and perfecting the structural quality of plasmonic structures (roughness) is the key step towards plasmonic applications in compact optical components and subwavelength imaging.

For profiled metal surfaces, the developed technique based on combined lithography and nanoimprint offers wafer-scale parallel fabrication of plasmonic components of high quality. Moving one step further toward 'active plasmonics' with efficient plasmonic-based emitters, controlled fabrication of metal nanoparticles (plasmonic metamaterials) is discussed for optical nanoantennae realization.

Acknowledgements. Support from the NABIIT project (contract No. 2106-05-033) and FTP project (274-07-0057) from the Danish Research Agency is gratefully acknowledged.

\section{References}

[1] W. L. Barnes, A. Dereux, and T. W. Ebbesen, Nature, vol. 424, pp. 824-830 (2003)

[2] S. I. Bozhevolnyi, et al., Phys. Rev. Lett., vol. 86, pp. 3008-3011 (2001)

[3] R. Charbonneau, et al., Optics Express, vol. 13, pp. 977-984 (2005); A. Boltasseva, et al., Journal of Lightw. Technol., vol. 23, pp. 413-422 (2005)

[4] K. Leosson, et al., Optics Express, vol. 14, pp. 314-319 (2006)

[5] S. I. Bozhevolnyi, et al., Phys. Rev. Lett., vol. 95, p. 046802 (2005); A. Boltasseva, et al., Optics Express, vol. 16 , pp. $5252-5260$ (2008)

[6] D. P. Fromm, et al., Nano Lett., vol. 4, pp. 957-961 (2004); P. Muhlschlegel, et al., Science, vol. 308, pp. 1607-1609 (2005)

[7] E. Cubukcu, et al., Appl. Phys. Lett., vol. 89, p. 093120 (2006)

[8] L. Chai and J. Klein, Langmuir, vol. 23, pp. 7777-83 (2007)

[9] N. Fang, H. Lee, and X. Zhang, Science, vol. 308, pp. 534-537 (2005)

[10] H.-K. Yuan, et al., Optics Express, vol. 15, 1076-1083 (2007); V. P. Drachev, et al., Optics Express, vol. 16, 1186-1195 (2008) 